\title{
GMR
}

\section{Overexpression of NaKR3 enhances salt tolerance in Arabidopsis}

\author{
Q. Luo ${ }^{1,2}$, Z. Zhao', D.K. Li', Y. Zhang' ${ }^{1}$, L.F. Xie' ${ }^{1}$, M.F. Peng ${ }^{1}$, S. Yuan ${ }^{3}$ and Y. Yang ${ }^{1,2}$ \\ ${ }^{1}$ Key Laboratory of Bio-Resources and Eco-Environment of Ministry of Education, \\ College of Life Sciences, Sichuan University, Chengdu, China \\ ${ }^{2}$ State Key Laboratory of Hydraulics and Mountain River Engineering, \\ Sichuan University, Chengdu, China \\ ${ }^{3}$ College of Resources and Environmental Sciences, Sichuan Agricultural University, \\ Chengdu, China \\ Corresponding author: Y. Yang \\ E-mail: yangyi528@scu.edu.cn \\ Genet. Mol. Res. 15 (1): gmr.15016378 \\ Received August 25, 2015 \\ Accepted January 7, 2016 \\ Published February 5, 2016 \\ DOI http://dx.doi.org/10.4238/gmr.15016378
}

ABSTRACT. Salinity is a major abiotic stress in agriculture. Here, we report that SODIUM POTASSIUM ROOT DEFECTIVE3 (NaKR3), which encodes a heavy metal-associated domain protein, is involved in salt tolerance in Arabidopsis. The results of quantitative reverse transcription-polymerase chain reaction analysis revealed that $N a K R 3$ was induced by high salinity and osmotic stresses, but not by $\mathrm{Cu}^{2+}$ stress. Transient expression of NaKR3-GFP in Arabidopsis protoplasts showed that the NaKR3 protein was localized in the cytosol. Transgenic Arabidopsis plants constitutively expressing NaKR3 under the control of the cauliflower mosaic virus $35 \mathrm{~S}$ promoter exhibited increased tolerance to salt treatment. Furthermore, overexpression of NaKR3 increased the expression of SOS1 and SOS3, but decreased the accumulation of salt-induced proline. Taken together, our results indicate that $\mathrm{NaKR} 3$ is involved in the salt stress response in Arabidopsis.

Key words: Abiotic stresses; NaKR3; Arabidopsis; Salt tolerance 


\section{INTRODUCTION}

Plants are sessile organisms and are therefore constantly challenged by various environmental stresses throughout their life cycle. Salinity is a major abiotic stress. Approximately $20 \%$ of the Earth land mass is affected by salinity, and $>50 \%$ of all arable lands will be saline by the year 2050 (Wang et al., 2003). To cope with such unfavorable growth conditions, plants have developed unique defense mechanisms and processes.

When plants grow in high-salinity conditions, the ability to control the $\mathrm{Na}^{+}$concentration is an essential process for survival. The amount of $\mathrm{Na}^{+}$in plants is determined by $\mathrm{Na}^{+}$influx and efflux, and these processes include $\mathrm{Na}^{+}$uptake from the soil, long distance transport to the shoot via the xylem, and redistribution through the phloem (Tester and Davenport, 2003; Apse and Blumwald, 2007). $\mathrm{Na}^{+}$influx, transport to the shoots, and distribution from the shoots to other parts of the plant have been extensively investigated (Tester and Davenport, 2003; Apse and Blumwald, 2007). However, the extent and mechanism of $\mathrm{Na}^{+}$recirculation in the phloem remains unclear. $\mathrm{Na}^{+}$recirculation is known to alter the $\mathrm{Na}^{+}$concentration in the leaves, thereby promoting $\mathrm{Na}^{+}$ tolerance (Munns and Tester, 2008). Berthomieu et al. (2003) proposed that AtHKT1 is related to $\mathrm{Na}^{+}$recirculation in the phloem; however, the current consensus is that AtHKT1 removes $\mathrm{Na}^{+}$from the xylem (Rus et al., 2006).

In Arabidopsis, a phloem-expressed gene, NaKR1, is thought to be related to $\mathrm{Na}^{+}$ transport. Tian et al. (2010) reported that loss of NaKR1 expression led to over accumulation of $\mathrm{Na}^{+}$and $\mathrm{K}^{+}$in the leaves. This finding implied that $\mathrm{NaKR} 1$ functions in the recirculation of $\mathrm{Na}^{+}$to the roots via the phloem, thereby limiting $\mathrm{Na}^{+}$accumulation in the leaves. NaKR1 has a heavy metal-associated (HMA) domain of 59 amino acids at the C-terminal end (Tian et al., 2010). Based on the results of NCBI-BLAST analysis, NaKR1 has one homologous protein in Arabidopsis; this protein, which shares $72 \%$ amino acid identity with NaKR1 at the C-terminal domain, is designated NaKR3 (Tian et al., 2010). In the present study, we showed that NaKR3 is related to salt resistance. Overexpression of NaKR3 increased the tolerance of plants to salt treatment. Our results indicate that NaKR3 is involved in salt stress-related signal transduction and provide a basis for further study the functions of NaKR3.

\section{MATERIAL AND METHODS}

\section{Plant material and growth conditions}

All Arabidopsis plants used in this study were the Columbia (Col-0) ecotype. Seeds were stratified at $4^{\circ} \mathrm{C}$ for 3 days and sterilized in $75 \%$ ethanol for $30 \mathrm{~s}$, followed by $\mathrm{HgCl}_{2}$ for 8 min. Sterilized seeds were thoroughly washed with sterile distilled water, and were then germinated either on Murashige and Skoog (MS) medium (Murashige and Skoog, 1962) or in soil. Germinated seedlings were cultivated in perlite/soil mixture in a growth chamber at $22^{\circ} \mathrm{C}$ under a $16-\mathrm{h}$ light/8-h dark cycle and at $60 \%$ humidity.

\section{Sequence analysis}

We identified 1150-bp putative cis elements in the promoter region of NaKR3, using a webbased signal scan search with the plant cis-acting regulatory DNA elements (PLACE) database (Higo et al., 1999). 


\section{Quantitative reverse transcription-polymerase chain reaction (qRT-PCR) analysis of gene expression}

Two-week-old seedlings cultivated on MS medium were treated with $50 \mu \mathrm{M} \mathrm{CuSO}_{4}, 250$ $\mathrm{mM} \mathrm{NaCl}$, or $300 \mathrm{mM}$ mannitol. Total RNA was isolated using RNAiso Plus (TaKaRa, Dalian, China) and was used for cDNA synthesis with the PrimeScript RT reagent Kit (TaKaRa, Shiga, Japan). DNA amplification was performed in the presence of FastStart SYBR Green Master (Roche, Mannheim, Germany) in an iCycler (Bio-Rad, Hercules, CA, USA), using the primer pairs ACTIN2-Q and NaKR3-Q shown in Table 1. The cycling conditions used were as follows: $95^{\circ} \mathrm{C}$ for $10 \mathrm{~min}$; and 45 cycles each at $95^{\circ} \mathrm{C}$ for $15 \mathrm{~s}$ and $60^{\circ} \mathrm{C}$ for $30 \mathrm{~s}$. All experiments were repeated three times independently. The raw data were quantitatively analyzed using the Bio-Rad iQ5 software. Data are reported as means $\pm S D$.

\begin{tabular}{|c|c|}
\hline Gene & Primer sequence 5'-3' \\
\hline \multirow{2}{*}{$\begin{array}{l}\text { ACTIN2-Q } \\
\text { (At1g49240) }\end{array}$} & F: GTTGACTACGAGCAGGAGATGG \\
\hline & R: ACAAACGAGGGCTGGAACAAG \\
\hline \multirow{2}{*}{$\begin{array}{l}\text { NaKR3-Q } \\
\text { (At3g53530) }\end{array}$} & F: TTCTTAGAGTGTCTCTCCACTGTCA \\
\hline & R: TGCAAAATCTATGTTGAAGGATGT \\
\hline \multirow{2}{*}{$\begin{array}{l}\text { NaKR3-221 } \\
\text { (At3g53530) }\end{array}$} & F: CGCTCTAGAATGAAAGCCGGTATGTTTTTATTG \\
\hline & R: CGCCCCGGGGGGGTTTCCGGATTTGCCC \\
\hline \multirow{2}{*}{$\begin{array}{l}\text { NaKR3-121 } \\
\text { (At3g53530) }\end{array}$} & F: CGCTCTAGAATGAAAGCCGGTATGTTTTATTG \\
\hline & R: CGCGAGCTCTTAGGTTTCCGGATTTGCCC \\
\hline \multirow{2}{*}{$\begin{array}{l}\text { SOS1-Q } \\
\text { (At2g01980) }\end{array}$} & F: GCAAACACTTTGATATTTATCCTCAG \\
\hline & R: CATGAATTCCCTTGGTAGGC \\
\hline \multirow{2}{*}{$\begin{array}{l}\text { SOS3-Q } \\
\text { (At5g24270) }\end{array}$} & F: CGAGCGAGAAGAATTGAAAGA \\
\hline & R: CGTTTTGCGGTCTGCTT \\
\hline
\end{tabular}

\section{Analysis of NaKR3 localization}

The NaKR3 coding region was cloned into the pBI221-GFP transient expression vector via the Xbal and Smal sites. The recombinant plasmids were introduced into Arabidopsis mesophyll protoplasts using polyethylene glycol-mediated transformation (Yoo et al., 2007). Expression of fusion protein was monitored after transformation, and images were viewed using confocal microscopy (LSM 510 META, Carl Zeiss, Oberkochen, Germany). The primer (NaKR3-221) used in this assay is shown in Table 1.

\section{Construction of transgenic plants}

To produce 35S::NaKR3 plants, NaKR3 cDNA was cloned into pBI121 (Clontech, Mountain View, CA, USA) via the $\mathrm{Xbal}$ and Sacl sites to replace the $\beta$-glucuronidase coding sequence. The obtained $\mathrm{pBI} 121-\mathrm{NaRK} 3$ construct was transformed into Agrobacterium tumefaciens strain EHA105 and was subsequently infiltrated into wild-type plants using the floral dip method (Clough and Bent, 1998). For phenotypic analysis, we used T3 homozygous lines. Data are reported as means \pm SD. The primers (NaKR3-121, ACTIN2-Q, and NaKR3-Q) used in this assay are listed in Table 1. 


\section{Salt tolerance tests}

For the salt tolerance test during seed germination, seeds of transgenic and wild-type plants were germinated on MS medium supplemented with $0,50,100,150$, or $200 \mathrm{mM} \mathrm{NaCl}$. The germination characteristics were observed every $24 \mathrm{~h}$. The experiments were repeated three times. Data are reported as means \pm SD. For the salt tolerance test during the post-germination stage, four-week-old plants were watered with $400 \mathrm{mM} \mathrm{NaCl}$ for 10 days.

\section{Analysis of the expression of salt stress-associated genes}

We investigated the expression of two salt-associated genes salt overly sensitive 1 (SOS1) and SOS3 in transgenic Arabidopsis plants using qRT-PCR analysis. Total RNA was isolated from two-week-old seedlings cultivated on MS medium. The primers (ACTIN2-Q, SOS1-Q, and SOS3-Q) used in this assay are listed in Table 1.

\section{Determination of proline content}

The proline content was determined as described previously (Bates et al., 1973). Fourweek-old seedlings cultivated in soil were treated with $400 \mathrm{mM} \mathrm{NaCl}$ for $12 \mathrm{~h}$. Proline was extracted from $300 \mathrm{mg}$ leaves by boiling for $10 \mathrm{~min}$ in $3 \mathrm{~mL} 3 \%(\mathrm{w} / \mathrm{v}) 5$-sulfosalicylic acid. The homogenate was centrifuged at $6000 \mathrm{rpm}$ for $10 \mathrm{~min}$ to obtain the supernatant as a proline crude extract. The reaction mixture containing $2 \mathrm{~mL}$ proline crude extract, $2 \mathrm{~mL}$ acetic acid, and $2 \mathrm{~mL} 2.5 \%(\mathrm{w} / \mathrm{v})$ acid-ninhydrin solution was boiled for $30 \mathrm{~min}$. Next, $4 \mathrm{~mL}$ methanol was added into the samples and $3 \mathrm{~mL}$ of the upper methanol layer solution was obtained. The proline content was analyzed spectrophotometrically at $520 \mathrm{~nm}$ using a spectrophotometer (Model 754, Shanghai, China) with five replicates for each proline content assay; the proline content was quantified based on a standard curve of pure proline. Data are reported as means \pm SD.

\section{RESULTS}

\section{NaKR3 expression is induced by abiotic stresses}

We analyzed the promoter region as far as $1150 \mathrm{bp}$ upstream of the NaKR3 gene using the PLACE database (Higo et al., 1999). We showed that a considerable number of potential cis-acting regulatory DNA elements exist. The predicted stress-responsive elements included a GT-1 box [involved in pathogen- and salt-induced gene expression (Park et al., 2004)], CCAAT box [involved in heat shock response (Chauhan et al., 2012)], MYC recognition site [binding site of ICE1, a major transcriptional activator of cold responsive genes (Lee et al., 2005)], and MYB recognition sites [important for dehydration-inducible expression (Abe et al., 2003)]. Our results suggest that NaKR3 is a stress-related gene.

To examine the induction patterns of NaKR3 in planta, we conducted qRT-PCR analysis of the expression of NaKR3 in Arabidopsis exposed to $50 \mu \mathrm{M} \mathrm{CuSO}_{4}, 250 \mathrm{mM} \mathrm{NaCl}$, or $300 \mathrm{mM}$ mannitol for different periods of time. We found that treatment with $50 \mu \mathrm{M} \mathrm{CuSO}_{4}$ had no significant effect on NaKR3 expression (Figure 1). In contrast, treatment with $250 \mathrm{mM} \mathrm{NaCl}$ or $300 \mathrm{mM}$ mannitol led to increased transcript levels of $N a K R 3$. After prolonged exposure to the $250 \mathrm{mM} \mathrm{NaCl}$ or $300 \mathrm{mM}$ mannitol, the expression of NaKR3 was markedly up-regulated in a time-dependent 
manner. After $8 \mathrm{~h}$ of exposure, gene expression was significantly increased (Figure 1), possibly because of salt stress. Our results suggest that NaKR3 is a salt- and osmotic stress-induced gene.

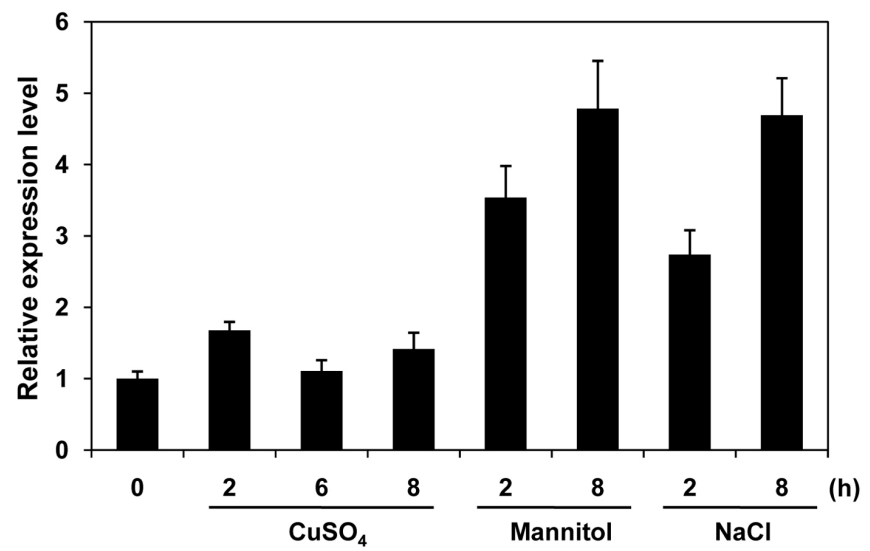

Figure 1. Quantitative reverse transcription-polymerase chain reaction analysis of the expression pattern of NaKR3 in response to different abiotic stress conditions. Total RNA was isolated from two-week-old Arabidopsis seedlings that were treated with $50 \mu \mathrm{M} \mathrm{CuSO}_{4}(2-8 \mathrm{~h}), 300 \mathrm{mM}$ mannitol $(2-8 \mathrm{~h})$, or $250 \mathrm{mM} \mathrm{NaCl}(2-8 \mathrm{~h})$. ACTIN2 was used as an internal control. Error bars indicate SD $(\mathrm{N}=3)$.

\section{NaKR3 is localized to the cytosol}

Subcellular localization prediction of NaKR3 based on WoLF PSORT (http://wolfpsort. seq.cbrc.jp/) revealed that NaKR3 may be localized to the chloroplast. To test this prediction, we transformed 35S:NaKR3-GFP and control 35S:GFP constructs into Arabidopsis mesophyll protoplasts using polyethylene glycol-mediated transformation. We found that NaKR3-GFP was localized to the cytosol (and not the chloroplast) (Figure 2), indicating that our subcellular localization prediction results require to be validated experimentally.

NaKR3-GFP

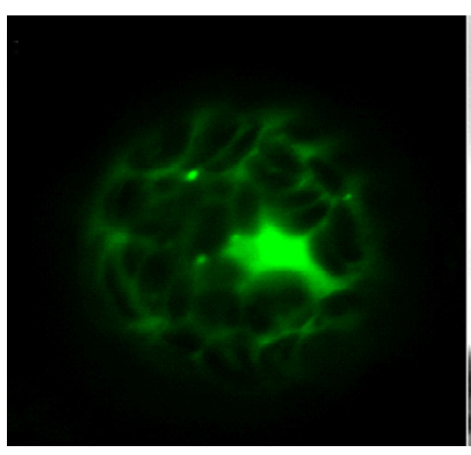

Figure 2. Subcellular localization of NaKR3. Confocal images of Arabidopsis protoplasts transiently expressing the NaKR3-GFP construct. 


\section{Overexpression of $N a K R 3$ enhances salt tolerance}

To further investigate the function of NaKR3 in vivo, we generated NaKR3 overexpressing (NaKR3-OE) lines. The coding region of NaKR3 was introduced into the pBI121 vector under the control of the CaMV 35S promoter, and the construct was then transformed into wild-type Arabidopsis plants. We obtained five independent T3 homozygous lines and confirmed the mRNA levels of NaKR3 expression in these lines using qRT-PCR analysis (Figure 3). We selected lines 4-1, 6-1, and 9-2 for further research.

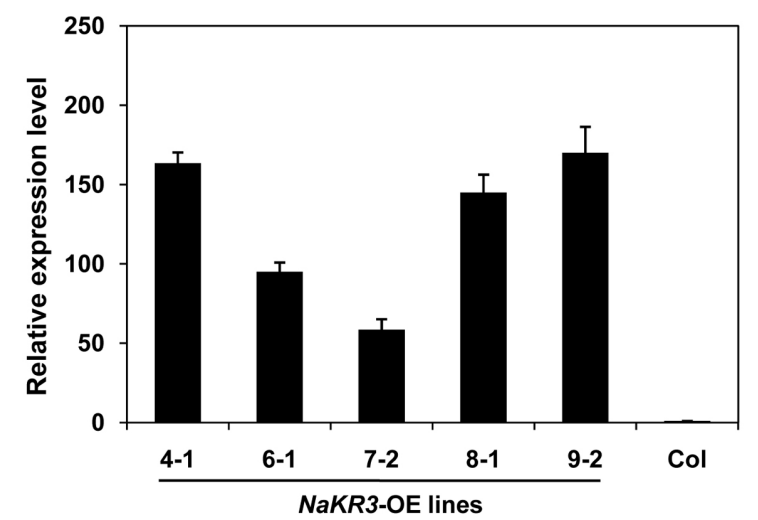

Figure 3. qRT-PCR analysis of NaKR3 expression in wild-type and NaKR3-OE lines. Total RNA was extracted from two-week-old seedlings. ACTIN2 was used as an internal control. Error bars indicate $S D(N=3)$.

As described above, NaKR3 is up-regulated by $\mathrm{NaCl}$. Hence, we examined whether overexpression of $\mathrm{NaRK} 3$ would affect $\mathrm{NaCl}$ sensitivity. First, we investigated the germination of NaKR3-OE and wild-type seeds on MS medium supplemented with 0, 100, 150, or $200 \mathrm{mM} \mathrm{NaCl}$. In the absence of $\mathrm{NaCl}, \mathrm{NaKR3-OE}$ lines and wild-type plants showed similar germination rates (Figure 4A). In contrast, on medium supplemented with 150 or $200 \mathrm{mM} \mathrm{NaCl}$, the germination rates of NaKR3-OE lines were significantly higher than those of wild-type plants. After 4 days of treatment with $150 \mathrm{mM} \mathrm{NaCl}$, the germination rates of the 4-1, 6-1, and 9-2 transgenic lines were $86.4,83.3$, and $85.3 \%$, respectively, whereas the germination rate of the control was only $60 \%$ (Figure 4B). We obtained similar results for plants cultivated on medium supplemented with $200 \mathrm{mM} \mathrm{NaCl}$ after 5 days. The germination rates of of the 4-1, 6-1, and 9-2 transgenic lines were $27.9,20.8$, and $56.3 \%$, whereas the germination rate of the wild-type was only $12.5 \%$ (Figure 4C). After 7 days, the germination of NaKR3-OE lines are higher than those of wild-type on medium supplemented with 150 or $200 \mathrm{mM} \mathrm{NaCl}$ (Figure 4D). Next, we monitored cotyledon greening after germination. We found that on medium supplemented with $100 \mathrm{mM} \mathrm{NaCl}$, most of NaKR3-OE lines displayed normal cotyledon greening, whereas less wild-type plants developed green cotyledons (Figure 5). To further investigate the effects of high salinity on post-germination growth, we treated soil-cultivated plants with $400 \mathrm{mM} \mathrm{NaCl}$. We found that before treatment, NaKR3-OE lines and wild-type plants grew well; moreover, the growth of NaKR3-OE lines did not differ markedly from that of wild-type plants (Figure 6). In contrast, after $\mathrm{NaCl}$ treatment, NaKR3-OE lines grew better than wild-type plants. Taken together, our results indicate that overexpression of NaKR3 enhances salt tolerance. 

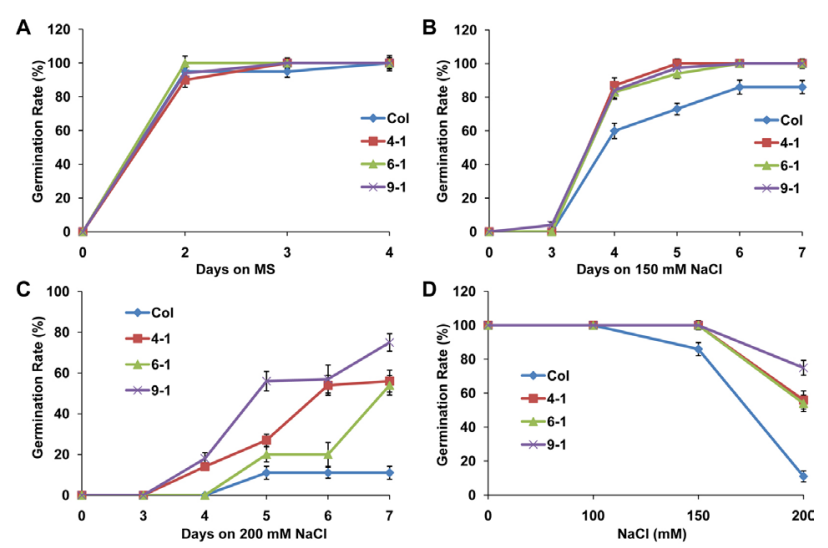

Figure 4. Seed germination in the absence and presence of $\mathrm{NaCl}$. A. Seed germination on Murashige and Skoog (MS) medium. B. Seed germination on MS medium supplemented with $150 \mathrm{mM} \mathrm{NaCl}$. C. Seed germination on MS medium supplemented with $200 \mathrm{mM} \mathrm{NaCl}$. D. Seed germination after 7 days on MS medium supplemented with different concentrations of $\mathrm{NaCl}$.
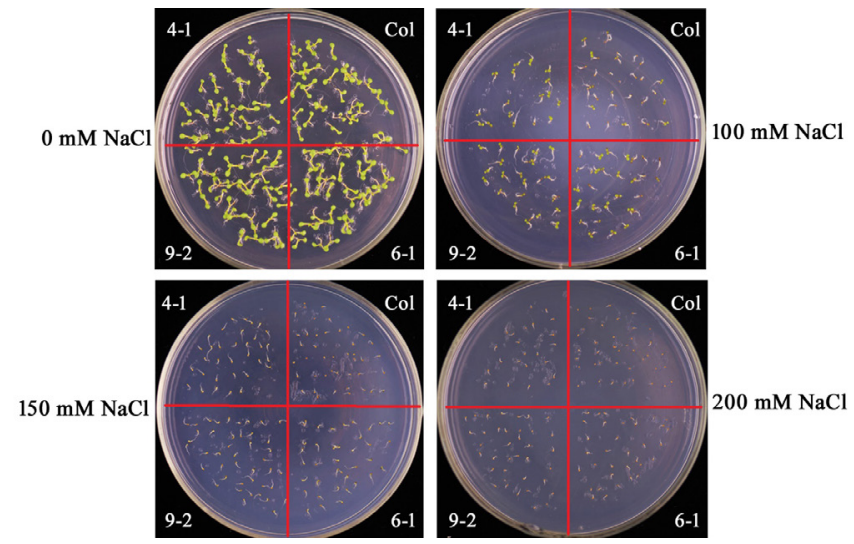

Figure 5. Seed germination on MS medium supplemented with $0,100,150$, or $200 \mathrm{mM} \mathrm{NaCl}$. All plates were photographed 7 days after imbibition.

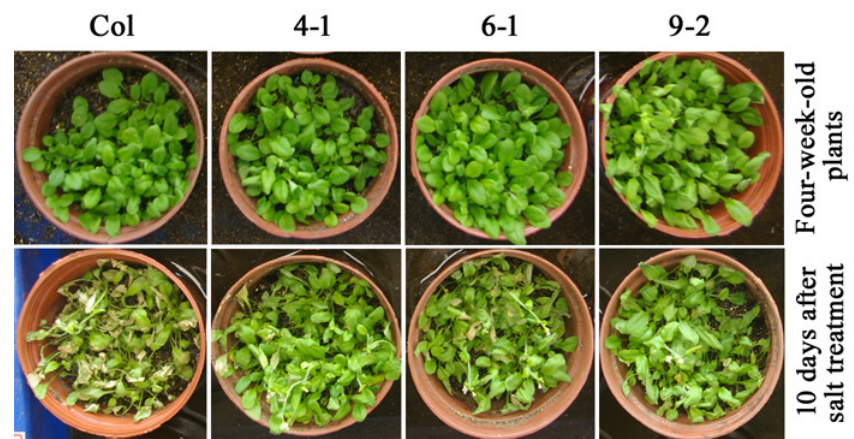

Figure 6. Salt tolerance test. Four-week-old plants were watered with $400 \mathrm{mM} \mathrm{NaCl}$ and were photographed after 10 days of treatment. 


\section{Overexpression of NaKR3 increases the expression of salt stress-associated genes}

To more fully elucidate the role of NaKR3 in salt tolerance, we investigated the expression of SOS1 and SOS3 in transgenic Arabidopsis plants. We found that under normal growth conditions, the expression of SOS1 and SOS3 was induced in NaKR3-OE plants (Figure 7A). Moreover, in comparison with wild-type plants, even the lowest expression levels of SOS1 and SOS3 in transgenic plants were approximately 3- and 2-fold higher, respectively.
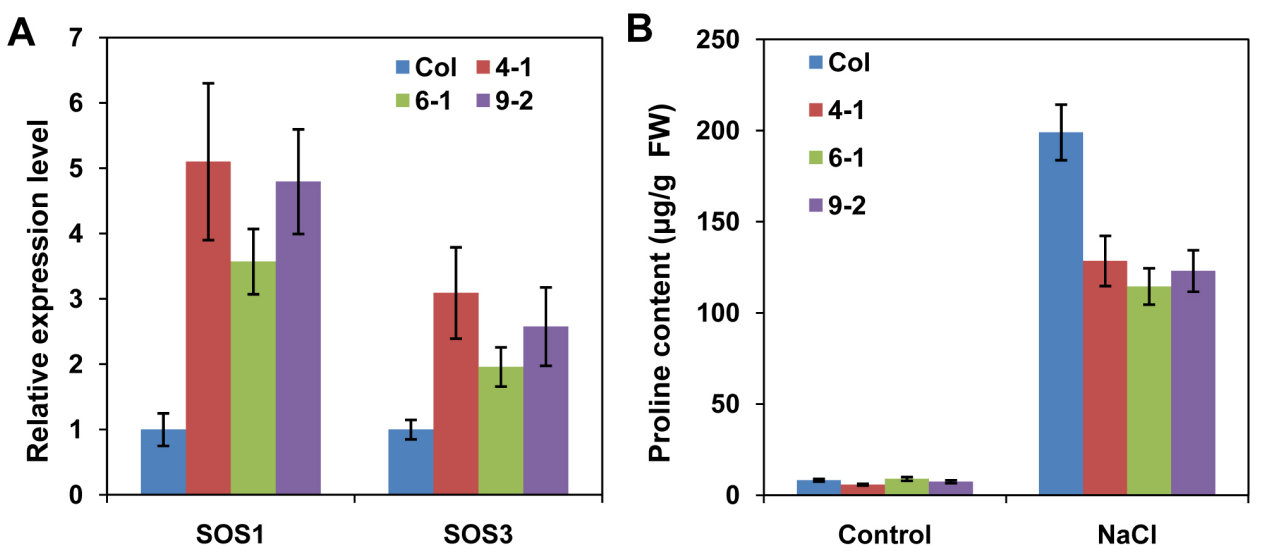

Figure 7. qRT-PCR analysis of SOS1 and SOS3 expression and measurement of proline content in wild-type and NaKR3-OE lines. A. qRT-PCR analysis of SOS1 and SOS3 expression in wild-type and NaRK3-OE lines. Total RNA was extracted from two-week-old seedlings. ACTIN2 was used as an internal control. Error bars indicate $\operatorname{SD}(\mathrm{N}=3)$. B. Proline content in the leaves of wild-type and NaKR3-OE lines before and after exposure to $400 \mathrm{NaCl}$ for $12 \mathrm{~h}$. Error bars indicate $\mathrm{SD}(\mathrm{N}=5)$.

\section{Proline accumulation in the leaves is higher in wild-type plants than in transgenic plants}

Proline accumulation is known to be critical for salt tolerance (Liu and Zhu, 1997); hence, we determined the proline contents in the leaves of wild-type and NaKR3-OE plants lines before and after exposure to $400 \mathrm{mM} \mathrm{NaCl}$. We found that before $\mathrm{NaCl}$ treatment, the proline content in the leaves did not differ significantly between wild-type plants and transgenic lines (Figure 7B). However, after $\mathrm{NaCl}$ treatment, the proline content in the leaves of wild-type plants and NaKR3-OE lines increased markedly. Moreover, the proline content increased more rapidly in the leaves of wild-type plants than in the leaves of transgenic lines (Figure 7B), and the final proline content in the leaves of wild-type plants was approximately 1.5-fold higher than that in the leaves of transgenic lines.

\section{DISCUSSION}

NaKR1 is a phloem mobile metal binding protein that plays an important role in $\mathrm{Na}^{+}$ transport (Tian et al., 2010). In the present study, we cloned NaKR3, which is a homolog of NaKR1, from Arabidopsis. We showed that NaKR3 expression was induced by $\mathrm{NaCl}$ and mannitol treatment. Transient expression of NaKR3-GFP in Arabidopsis protoplasts indicated that NaKR3 is localized in the cytosol; this finding is consistent with the subcellular localization of NaKR1 (Tian et 
al., 2010). Transgenic lines overexpressing NaKR3 exhibited enhanced tolerance to salt stress, as well as decreased salt-induced proline accumulation. Our results suggest that NaKR3 is involved in the salt stress response in Arabidopsis.

The results of protein domain analysis revealed that, similar to NaKR1, NaKR3 has a HMA domain at the C-terminus. The HMA domain exists in proteins that function in the transfer and/or binding of heavy metals; these proteins include heavy metal transporters, metallochaperones, and enzymes that use heavy metals as cofactors (Dykema et al., 1999; Tian et al., 2010). Tian et al. (2010) reported that $\mathrm{Zn}, \mathrm{Cu}, \mathrm{Fe}, \mathrm{Ni}$, and Co were associated with the NaKR1 protein. On the other hand, the HMA domain of NaKR3 shares low sequence similarity with the Arabidopsis HMA domain protein $\mathrm{CCH}$; this protein is found in the phloem and is thought to transport $\mathrm{Cu}$ out of senescing tissues (Mira et al., 2001). This may explain why the expression of $\mathrm{NaKR} 3$ was not affected by $\mathrm{Cu}^{2+}$ in our present study.

Previous studies have shown that $\mathrm{Na}^{+}$transport is related to salt tolerance. For example, HKT1 - a $\mathrm{Na}^{+}-\mathrm{K}^{+}$co-transporter - decreases $\mathrm{Na}^{+}$accumulation by excluding $\mathrm{Na}^{+}$from the shoots, thereby leading to increased salt tolerance (Rubio et al., 1995; Rus et al., 2001, 2006). In the present study, we found that NaKR3, which is a homolog of NaKR1 - a Na+ transport protein - was involved in salt tolerance. Overexpression of NaKR3 enhanced the salt tolerance of transgenic Arabidopsis lines. Our findings provide further evidence for the relationship between $\mathrm{Na}^{+}$transport and salt tolerance.

The SOS pathway plays an important role in the plant response to salt stress (Zhu, 2002). Accordingly, Arabidopsis plants overexpressing SOS1 and SOS3 showed significantly increased salt tolerance (Liu and Zhu, 1998; Shi et al., 2000). In the present study, we demonstrated that overexpression of NaRK3 increased the expression of SOS1 and SOS3, indicating that NaRK3 may be involved in salt tolerance through regulating downstream signal molecules such as SOS1and SOS3 in the SOS pathway.

Proline acts as an organic solute in plants. Free proline levels increase when plants suffer from abiotic stresses such as cold, drought, and high salt (Hare et al., 1998). In the present study, we examined the free proline content in wild-type plants and NaKR3-OE lines. We showed that NaKR3-OE lines had lower free proline levels than wild-type plants. Our results are inconsistent with those of previous studies, in which overexpression salt tolerance genes was generally shown to confer higher proline levels (Liu et al., 2007; Gao et al., 2010; Xu et al., 2010). However, some salt tolerance genes play similar roles to NaKR3. For example, the sos/ mutant of Arabidopsis thaliana is extremely sensitive to salt stress, but accumulates lower amounts of free proline than the wild-type (Liu and Zhu, 1997). In the present study, the observed increase in proline accumulation was likely a symptom of stress injury rather than an indicator of stress tolerance.

In conclusion, in the present study, we identified a new salt stress-related gene, NaKR3, in Arabidopsis. We showed that overexpression of this gene confers enhanced tolerance to salt stress. We propose that NaKR3 represents a potential candidate for engineering of stress-tolerant crops.

\section{Conflicts of interest}

The authors declare no conflict of interest.

\section{ACKNOWLEDGMENTS}

Research supported by grants from the National Natural Science Foundation of China (\#31171586 and \#31271758) and the National "973" Project (\#2013CB733903). 


\section{REFERENCES}

Abe H, Urao T, Ito T, Seki M, et al. (2003). Arabidopsis AtMYC2 (bHLH) and AtMYB2 (MYB) function as transcriptional activators in abscisic acid signaling. Plant Cell 15: 63-78. http://dx.doi.org/10.1105/tpc.006130

Apse MP and Blumwald E (2007). $\mathrm{Na}^{+}$transport in plants. FEBS Lett. 581: 2247-2254. http://dx.doi.org/10.1016/j.febslet.2007.04.014

Bates LS, Waldren RP and Teare ID (1973). Rapid determination of free proline for water-stress studies. Plant Soil 39: 205-207. http://dx.doi.org/10.1007/BF00018060

Berthomieu P, Conéjéro G, Nublat A, Brackenbury WJ, et al. (2003). Functional analysis of AtHKT1 in Arabidopsis shows that $\mathrm{Na}\left({ }^{+}\right)$recirculation by the phloem is crucial for salt tolerance. EMBO J. 22: 2004-2014. http://dx.doi.org/10.1093/emboj/cdg207

Chauhan H, Khurana N, Nijhavan A, Khurana JP, et al. (2012). The wheat chloroplastic small heat shock protein (sHSP26) is involved in seed maturation and germination and imparts tolerance to heat stress. Plant Cell Environ. 35: 1912-1931. http://dx.doi.org/10.1111/j.1365-3040.2012.02525.x

Clough SJ and Bent AF (1998). Floral dip: a simplified method for Agrobacterium-mediated transformation of Arabidopsis thaliana. Plant J. 16: 735-743. http://dx.doi.org/10.1046/j.1365-313x.1998.00343.x

Dykema PE, Sipes PR, Marie A, Biermann BJ, et al. (1999). A new class of proteins capable of binding transition metals. Plant Mol. Biol. 41: 139-150. http://dx.doi.org/10.1023/A:1006367609556

Gao Z, He X, Zhao B, Zhou C, et al. (2010). Overexpressing a putative aquaporin gene from wheat, TaNIP, enhances salt tolerance in transgenic Arabidopsis. Plant Cell Physiol. 51: 767-775. http://dx.doi.org/10.1093/pcp/pcq036

Hare PD, Cress WA and Van Staden J (1998). Dissecting the roles of osmolyte accumulation during stress. Plant Cell Environ. 21: 535-553. http://dx.doi.org/10.1046/j.1365-3040.1998.00309.x

Higo K, Ugawa Y, Iwamoto M and Korenaga T (1999). Plant cis-acting regulatory DNA elements (PLACE) database: 1999. Nucleic Acids Res. 27: 297-300. http://dx.doi.org/10.1093/nar/27.1.297

Lee BH, Henderson DA and Zhu JK (2005). The Arabidopsis cold-responsive transcriptome and its regulation by ICE1. Plant Cell 17: 3155-3175. http://dx.doi.org/10.1105/tpc.105.035568

Liu J and Zhu JK (1997). Proline accumulation and salt-stress-induced gene expression in a salt-hypersensitive mutant of Arabidopsis. Plant Physiol. 114: 591-596. http://dx.doi.org/10.1104/pp.114.2.591

Liu J and Zhu JK (1998). A calcium sensor homolog required for plant salt tolerance. Science 280: 1943-1945. http://dx.doi.org/10.1126/science.280.5371.1943

Liu K, Wang L, Xu Y, Chen N, et al. (2007). Overexpression of OsCOIN, a putative cold inducible zinc finger protein, increased tolerance to chilling, salt and drought, and enhanced proline level in rice. Planta 226: 1007-1016. http://dx.doi.org/10.1007/s00425-007-0548-5

Mira H, Martínez-García F and Peñarrubia L (2001). Evidence for the plant-specific intercellular transport of the Arabidopsis copper chaperone CCH. Plant J. 25: 521-528. http://dx.doi.org/10.1046/j.1365-313x.2001.00985.x

Munns R and Tester M (2008). Mechanisms of salinity tolerance. Annu. Rev. Plant Biol. 59: 651-681. http://dx.doi.org/10.1146/annurev.arplant.59.032607.092911

Murashige T and Skoog F (1962). A revised medium for rapid growth and bio assays with tobacco tissue cultures. Physiol. Plant. 15: 473-497. http://dx.doi.org/10.1111/j.1399-3054.1962.tb08052.x

Park HC, Kim ML, Kang YH, Jeon JM, et al. (2004). Pathogen- and NaCl-induced expression of the SCaM-4 promoter is mediated in part by a GT-1 box that interacts with a GT-1-like transcription factor. Plant Physiol. 135: 2150-2161. http://dx.doi.org/10.1104/pp.104.041442

Rubio F, Gassmann W and Schroeder JI (1995). Sodium-driven potassium uptake by the plant potassium transporter HKT1 and mutations conferring salt tolerance. Science 270: 1660-1663. http://dx.doi.org/10.1126/science. 270.5242 .1660

Rus A, Yokoi S, Sharkhuu A, Reddy M, et al. (2001). AtHKT1 is a salt tolerance determinant that controls $\mathrm{Na}\left({ }^{+}\right)$entry into plant roots. Proc. Natl. Acad. Sci. USA 98: 14150-14155. http://dx.doi.org/10.1073/pnas.241501798

Rus A, Baxter I, Muthukumar B, Gustin J, et al. (2006). Natural variants of AtHKT1 enhance $\mathrm{Na}^{+}$accumulation in two wild populations of Arabidopsis. PLoS Genet. 2: e210. http://dx.doi.org/10.1371/journal.pgen.0020210

Shi H, Ishitani M, Kim C and Zhu JK (2000). The Arabidopsis thaliana salt tolerance gene SOS1 encodes a putative $\mathrm{Na}^{+} / \mathrm{H}^{+}$ antiporter. Proc. Natl. Acad. Sci. USA 97: 6896-6901.http://dx.doi.org/10.1073/pnas.120170197

Tester M and Davenport R (2003). $\mathrm{Na}^{+}$tolerance and $\mathrm{Na}^{+}$transport in higher plants. Ann. Bot. (Lond.) 91: 503-527. http://dx.doi.org/10.1093/aob/mcg058

Tian H, Baxter IR, Lahner B, Reinders A, et al. (2010). Arabidopsis NPCC6/NaKR1 is a phloem mobile metal binding protein necessary for phloem function and root meristem maintenance. Plant Cell 22: 3963-3979. http://dx.doi.org/10.1105/tpc.110.080010 
Wang W, Vinocur B and Altman A (2003). Plant responses to drought, salinity and extreme temperatures: towards genetic engineering for stress tolerance. Planta 218: 1-14. http://dx.doi.org/10.1007/s00425-003-1105-5

Xu J, Tian YS, Peng RH, Xiong AS, et al. (2010). AtCPK6, a functionally redundant and positive regulator involved in salt/ drought stress tolerance in Arabidopsis. Planta 231: 1251-1260. http://dx.doi.org/10.1007/s00425-010-1122-0

Yoo S-D, Cho Y-H and Sheen J (2007). Arabidopsis mesophyll protoplasts: a versatile cell system for transient gene expression analysis. Nat. Protoc. 2: 1565-1572. http://dx.doi.org/10.1038/nprot.2007.199

Zhu JK (2002). Salt and drought stress signal transduction in plants. Annu. Rev. Plant Biol. 53: 247-273. http://dx.doi.org/10.1146/annurev.arplant.53.091401.143329 